\title{
Slam Poetry: entre os impasses da crítica e da criação
}

\author{
Paulo Eduardo Benites de Moraes ${ }^{1}$ \\ Universidade Federal de Rondônia - UNIR, Porto Velho, Rondônia, Brasil \\ Patrícia Pereira da Silva ${ }^{2}$ \\ Universidade Federal de Rondônia - UNIR, Porto Velho, Rondônia, Brasil
}

Resumo: Este artigo tem como objetivo discutir, à luz da crítica literária, a prática de leitura de poesia hoje. O recorte proposto em nossa discussão toma como foco de análise a leitura de poesia e sua abordagem crítica e analítica no contexto acadêmico das universidades brasileiras. Para tanto, traçamos um percurso metodológico que compreende os seguintes passos: 1) apresentar os impasses enfrentados pela crítica literária universitária, com especial atenção à poesia; 2) debater algumas das hipóteses mais recentes no que diz respeito à crítica de poesia; 3) pensar a crítica de poesia como prática situada. Neste último ponto, nossa ênfase recai na produção poética da periferia, sobretudo o slam poetry conduzido por mulheres, a partir da qual defendemos a hipótese de que ler poesia hoje demanda a inserção do (olhar) crítico no contexto social e cultural dos poetas, o que demanda uma expansão do ato de ler poesia para apreender questões que intercruzam o estético, o político e o ético.

Palavras-chave: Crítica; Leitura; Poesia Contemporânea; Periferia.

Title: Slam Poetry: between the impasses of criticism and creation

Abstract: This paper aims to discuss, under the perspective of literary criticism, the practice of reading poetry today. The perspective proposed in our discussion focuses on the analysis of poetry reading and its critical and analytical approach at the Brazilian university. To this end, we draw a methodological path that comprises the following steps: 1) the impasses faced by university literary critics, with special attention to poetry; 2) some of the most recent hypotheses with regard to poetry criticism; 3 ) the criticism of poetry as a situated practice. In this last point, our emphasis is on the poetic production of the socalled peripheral literature made by women from which we defend the hypothesis that reading poetry today demands the insertion of the critic in the social and cultural context of the poets, which demands an expansion of theoretical repertoire to apprehend issues that intersect the aesthetic, the political and the ethical.

Keywords: Criticism; Reading; Contemporary poetry; Peripheral literature.

\footnotetext{
${ }^{1}$ Doutor em Estudos Literários pela Universidade Federal de Mato Grosso do Sul (UFMS). Docente do Departamento de Línguas Estrangeiras e do Programa de Pós-Graduação em Estudos Literários da Universidade Federal de Rondônia. Líder do Grupo de Pesquisa em Poéticas Moderna e Contemporânea (UNIR/CNPq). Orcid: https://orcid.org/0000-0002-5809-0956 E-mail: paulo.moraes@unir.br

${ }^{2}$ Mestranda em Estudos Literários (MEL) da Universidade Federal de Rondônia (UNIR). Pesquisadora do Grupo de Pesquisa em Poéticas Moderna e Contemporânea (CNPq/UNIR). Orcid: https://orcid.org/0000-0002-2325-6581 E-mail: patthypds@gmail.com
} 
FADIGA

sozinha

penélope desfia desafia

abutres, o filho, a multidão

mas os deuses aplaudem ulisses (ROMÃO, p. 117, 2019)

\section{Considerações Iniciais}

Em Crítica literária: em busca do tempo perdido? (2011), o professor e crítico João Cezar de Castro Rocha, após realizar um percurso exploratório e profundo em torno da historiografia da crítica literária, sobretudo no Brasil, aponta um desafio que ainda hoje, uma década depois, nos assombra: "[...] necessitamos estreitar os laços entre a produção do conhecimento e a apropriação do saber pela sociedade" (ROCHA, 2011, p. 381). Como produção do conhecimento, podemos entender a função exercida pela crítica literária universitária. Como apropriação do saber pela sociedade, compreende-se, em última instância e em especial atenção ao que nos interessa neste ensaio, a formação do leitor em termos de leitura poética.

A discussão, todavia, não é tão simples como pode parecer. Para introduzirmos, de maneira mais apropriada a questão, destacamos um termo mencionado no parágrafo anterior: produção de conhecimento. 0 termo mais problemático dessa questão parece ser exatamente a concepção de produção com a qual a crítica literária universitária tem enfrentado. Para tanto, se faz necessário apresentar, em um primeiro momento, as implicações da produção acadêmica no trabalho crítico, em especial o da teoria literária, de modo mais particular ainda o trabalho de leitura crítica de poesia hoje. Em um segundo momento, o objetivo é apresentar caminhos que respondem a esse contexto de produção acadêmica, de modo a nos oferecer propostas teóricas e metodológicas no que diz respeito ao estudo e aos modos de ler poesia hoje. Para cumprir esse objetivo, destacamos os trabalhos que vêm sendo produzidos com as poéticas da periferia, como é o caso do Slam Poetry.

\section{0 impasse da crítica literária hoje}

Nosso ponto de saída, para retomarmos a citação de Castro Rocha em nossas considerações iniciais, leva em conta o exercício de pensamento como elemento privilegiado do trabalho de crítica literária e de produção de conhecimento. Nesse sentido, esse trabalho de investigação deve ser lido, de acordo com os propósitos do presente texto, como uma 
forma de criação, uma vez que implica o universo das ideias e da reflexão crítica. Claro que se trata, nesse ponto, de uma criação diferente do campo das artes. Em outros termos, estamos pensando desde a possibilidade de contemplar detidamente as ideias, ao mesmo tempo em que se busca a forma de expressão ideal ou mais adequada à natureza da argumentação. Pensar e escrever, nesse sentido, também implicam originalidade do estilo, forma de expressão a partir da qual as ideias são representadas. Originalidade argumentativa, acuidade reflexiva e estilo são elementos imprescindíveis ao pensamento; no entanto, o nó da questão se dá, como expõe o também professor e crítico Márcio Scheel,

quando o trabalho intelectual se encontra acuado pelas demandas da produtividade em escala, da linha de produção analítica, da publicação em vistas das exigências institucionais, o que interessa é menos o alcance e a influência das ideias, e mais os índices que garantem os relatórios avaliativos. (SCHEEL, 2017, p. 110).

Em outros termos, o próprio Scheel chamou isso de "institucionalização do pensamento e da reflexão teórica" (SCHEEL, 2017, p. 114). Pensando nesses termos, a direção do argumento segue a ideia de que a teoria da literatura está confinada, sobremaneira, à universidade. Todavia, como autor assinalou em seu texto, a raiz do problema não se deve ao fato de a teoria literária estar confinada à universidade, simplesmente, mas sim ao modo como se pensa e se produz conhecimento dentro da universidade, hoje.

O modelo de construção de conhecimento ao qual estamos submetidos, isso em termos de produção científica, se converteu em racionalidade institucional e esta, por sua vez, cria a racionalização burocrática, que condiciona todo o trabalho de pesquisa ao imediatismo da publicação especializada. Em resumo, para concluirmos a linha argumentativa do professor Márcio Scheel com a qual concordamos, "[...] a publicação, resultado da reflexão crítica e da pesquisa sistemática, acaba reduzida à condição de mercadoria, ao passo que o trabalho intelectual mal consegue dissimular sua natureza fabril". (SCHEEL, 2017, p. 108). Nos parece, portanto, que a permanência do desafio levantado por Castro Rocha, de que o conhecimento está cada vez mais distante da sociedade, tem como uma de suas características o fato de o conhecimento científico estar confinado à sua própria dinâmica e à serviço de seus próprios interesses, o que instaurou uma crise da própria crítica.

Se em outros tempos, como pondera Paulo Franchetti (2016, p. 115-116), houve uma integração total entre o fazer literário e a crítica, um esforço que se pode definir como a "construção de normas, de padrões civilizacionais que não só definissem, mas também promovessem a unidade nacional, enfrentando o fantasma da fragmentação cultural e política do vasto território", nos dias de hoje o papel da crítica parece ter perdido esse lugar privilegiado. Tal discussão passa pela noção de literatura como um imperativo nacionalista. 0 norte da vida cultural buscava a promoção de uma ideia de identidade nacional, e nesse ponto a crítica literária desempenhava papel relevante contribuindo com a formação 
intelectual do sujeito, uma vez que a educação literária dispunha de prestígio na sociedade. No Brasil, nessa época, é possível perceber o esforço dos intelectuais em projetar a unidade nacional por meio da língua, pressupondo de imediato que a Língua Portuguesa carecia ocupar um lugar de hegemonia não só no cenário nacional, mas principalmente que garantisse a integração do Brasil no Ocidente. A resposta a isso surge com a motivação de se criar um padrão linguístico no país. Mário de Andrade é um dos nomes que problematizaram essa questão. Em texto de 1939 ele afirma:

Não é possível a gente ser claro, pois não há uma claridade normalizada de expressão e cada um é claro só para consigo mesmo; não é possível ser sutil, pois que tudo são sutilezas de um individualismo desbragado; não é possível elegância onde não há conformidade; não é possível vigor verdadeiro, certeza, mecanismo, abstração, pois que tudo é sumarento, é desregramento, desobediência e espontaneidade (ANDRADE, 1972, p. 35)

Como adverte Franchetti, é sob o prisma desse texto de Mário de Andrade que se deveria ler o que se propõe em "A língua viva", texto clássico de Mário de Andrade. O fato preponderante nesse contexto é que a crítica teria um papel bastante definido a esse respeito, a saber: "caberia a ela identificar, no meio da aluvião de obras em que, a falta de domínio técnico e conhecimento da língua culta produzem efeitos de pouca importância, aquelas que de fato sejam relevantes para desenhar a imagem da cultura de uma fase" (FRANCHETTI, 2016, p. 117). Em contraste com esse tempo descrito por Franchetti, o Século XXI marca uma mudança nos rumos da crítica literária, não mais como sendo a expressão de um padrão culto da cultura, mas agora vinculada necessariamente ao espaço acadêmicouniversitário.

Jaime Ginzburg, em interessante artigo sobre a produção acadêmica na área de Letras, aponta para um antagonismo:

existe uma assimetria entre a produção e a leitura, no seguinte sentido: o interesse de docentes em publicar artigos em revistas $\mathrm{A} 1$ ou $\mathrm{A} 2$ é um elemento relativamente independente da consideração de conteúdos das revistas na elaboração de novas pesquisas. É possível que livros e capítulos de livros tenham um papel mais central, na fundamentação de pesquisas, do que periódicos acadêmicos, em estudos literários e em outras áreas. (GINZBURG, 2014, p. 11).

A assimetria apontada por Ginzburg desvela um impasse grave porque passa a crítica literária, qual seja: uma relação inconsistente entre a valorização de um único canal de divulgação científica (os periódicos) e a interlocução dentro da comunidade acadêmica no sentido de discussão de ideias. Tem-se visto um trabalho inócuo no que tange ao exercício da crítica literária em tempos de CAPES e relatórios, uma vez que cresce o volume e a cobrança da produção científica/crítica, que se tornou sinônimo de publicação, em detrimento da qualificação e do debate de ideias. A produção da crítica literária parece ter assumido um papel meramente institucional e burocrático, com fins de pontuar em avaliações 
institucionais.

Dentro desse escopo, a crítica de poesia - que tem um interesse particular para o presente artigo - tem passado pela mesma assimetria. Cresce o número de autores e possibilidades de publicações de obras de poesia, mas diminui vertiginosamente a relevância de se ler poesia hoje. Resta perguntar quais as razões pelas quais a poesia tem perdido relevância social? O poeta Ricardo Domeneck, em texto esclarecedor, argumenta que "a poesia parece ter sido reduzida a uma espécie de bibelô cultural, sofrendo a perda de papel de investigação sistemática e de processo epistemológico, e parece retornar ao contexto de entretenimento sofisticado, prática de bom gosto, catequese moral" (DOMENECK, 2006, p. 177). Isso significa, de modo sério, que uma prática artística como a poesia que dispunha, até pouco tempo, de um certo prestígio e de uma força vital para a resistência, ao perder sua força de combate e cair num espaço tão domesticado, precisa ser repensada quanto ao seu fazer estético e se há ainda a necessidade de continuar a fazê-la.

Essa constatação, um tanto catastrófica, carece de um esclarecimento minimamente mais adequado. Não se acredita aqui que a poesia necessite da ajuda da crítica literária para que ela retome seu prestígio. Todavia, o que parece ser o ponto nevrálgico da discussão diz respeito ao papel formativo que a crítica assumiu, ou seja, criou-se a necessidade de que a crítica venha, em nome da poesia, explica-la ou interpretá-la ao público, de modo que a poesia, supostamente entendida como um gênero enigmático e de acesso restrito aos doutos, tivesse a necessidade de uma formação prévia que só a crítica especializada pudesse transmitir.

O caminho que nos propomos a pensar aqui, ao contrário, não entende a crítica como um campo de conhecimento no qual se possa ofertar uma formação ao sujeito. Em outros termos, o papel da crítica não deveria ser, em seu fim, o da formação de leitores, ou melhor, talvez este não seja seu objetivo mais importante. Ao contrário, mesmo que o exercício da crítica possa se dar em sala de aula, a crítica literária deve implicar uma atividade especulativa em relação a um texto, algo como um exercício de reflexão que possa situar o texto no tempo e no espaço e percebê-lo como um corpo estético problematizador, que nos force a levantar questões. Se há alguma função educativa na tarefa da crítica, a pensamos aqui conforme T. W. Adorno em seu entendimento do que seja educação:

Creio que isto se vincula intimamente ao próprio conceito de racionalidade ou de consciência. Em geral este conceito é apreendido de um modo excessivamente estreito, como capacidade formal de pensar. Mas esta constitui uma limitação da inteligência, um caso especial da inteligência, de que certamente há necessidade. Mas aquilo que caracteriza propriamente a consciência é o pensar em relação à realidade, ao conteúdo - a relação entre as formas e estruturas de pensamento do sujeito e aquilo que este não é. (ADORNO, 2006, p. 151)

De acordo com Adorno, então, a capacidade educativa de formar uma consciência crítica deve passar, necessariamente, pela capacidade de pensar e de articular esse pensamento com as diversas maneiras de experenciar o mundo que nos circunda. Se o 
exercício do pensamento crítico está no campo do intercâmbio das experiências, o problema que enfrentamos hoje perpassa pela questão do empobrecimento dessas mesmas experiências. O pensamento de Walter Benjamin, em "Experiência e Pobreza" (2018), é, nesse ponto, nosso principal referencial, sobretudo por articular de modo dialético as relações entre o que se perde e o que se ganha com a perda. Dito de outro modo, o contexto ao qual Benjamin se refere diz respeito não somente às experiências privadas, mas também às coletivas, as quais apontam para "a pobreza de experiências no plano de toda a humanidade" (BENJAMIN, 2018, p. 86). O ponto de inflexão do pensamento de Benjamin reside no que ele denomina de "nova barbárie", isto é, "um novo conceito, positivo, de barbárie", a partir do qual, a nova pobreza "leva o bárbaro a começar tudo de novo, a voltar ao princípio, a saber viver com pouco, a construir algo com esse pouco, sem olhar nem à esquerda nem à direita" (BENJAMIN, 2018, p. 87).

Nesse sentido, considerar a referência a esse empobrecimento é um exercício crítico. No caso da poesia, como assinalado por Domeneck, não temos como nos desviar da presença dos produtos da indústria cultural que apontam mais para o campo do entretenimento do que o da experiência estética. Nesse contexto, a crítica encontra-se na fissura entre o que segue no ensino universitário, com manifesta preferência a obras canônicas e teorias já consagradas, e o que está posto no cotidiano dos sujeitos e na educação básica. Logo, tomar consciência de seu próprio lugar pode ser uma maneira de a crítica lançar questões aos problemas que perpassam pelo texto literário como expressão estética.

Não se argumenta aqui, entretanto, em favor de uma dependência entre a criação e a crítica. Sobre esse tema, convém observar, rapidamente, uma postura cultuada no Brasil na década de 1970, exposta por Silviano Santiago ao estudar as produções dessa fase: "esse novo discurso poético que vai surgindo levará obrigatoriamente o crítico (que sempre vem a reboque) a reconsiderar o acervo literário, instituindo novos títulos e novos nomes do passado" (SANTIAGO, 2000, p. 189). O uso do destaque dos parênteses e do advérbio impositivo não deixam nenhuma alternativa à crítica, qual seja: o sintoma de uma escrita teórica que se satisfaz em permanecer inelutavelmente rebocada, à sombra do texto literário. Estabelecendo um contraponto a essa visão, Alberto Pucheu escreve: "o implícito na citação acima (explicitado em algumas passagens do livro) parece ser que o crítico pode se antecipar a outros críticos e leitores, mas - jamais - ao criador primeiro, que, sempre, o sombreia" (PUCHEU, 2014, p. 258).

O giro teórico para esse impasse surge com a leitura das ideias e do pensamento de latino-americano: o esforço da heteronomia. Florencia Garramuño tece a seguinte reflexão:

Nessa poética do tato, a poesia já não se postula como cápsula autônoma marcada por um princípio limpo de forma, mas revela uma vulnerabilidade tanto do sujeito quanto do poema face ao mundo. Parece-me que essa vulnerabilidade pode ser pensada como uma heteronomia, já que a poesia se concebe como uma exploração do real na qual esse exterior serve mais do que como referência da poesia, como o objeto mesmo que impõe lógicas amiúde desestabilizadoras e contraditórias tanto 
da obra quanto de um sujeito que permanece imune ante o desafio do mundo. (GARRAMUÑO, 2008, p. 88-89).

A postura crítica de Garramuño explora um caminho expandido. Ao apontar para uma ultrapassagem da autonomia literária, isto é, uma nova possibilidade na esfera do cotidiano e da criação em que, ao invés de cada um aniquilar sua alteridade, deixam suas camadas visíveis em transparências atuantes, além de abrir tanto a literatura quanto a crítica a inúmeras possibilidades muito além das formalistas e das conhecidas, a intensidade maior da literatura não Ihe seria mais exclusiva, podendo ser atingida igualmente por modalidades outras. Essa contaminação heteronômica, bem como a possibilidade de a arte atuar nesse campo expandido, promove uma transformação nos sentidos e usos possíveis da arte na sociedade contemporânea, e o papel da crítica literária parece dividir espaço com outros campos do conhecimento. Diante disso, passemos agora à discussão de obras e autores que enfrentam essa questão, seja no campo da crítica, seja no campo da criação, ou mesmo na indiscernibilidade entre essas duas formas de pensamento.

\section{A crítica literária e a sua prática situada}

Se iniciamos este ensaio com a problematização de Castro Rocha (2011) de que o trabalho da crítica e o conhecimento por ele produzido não encontram sentido no processo de formação de leitores, a saída para este impasse, como vem apontando os mesmos estudiosos, é repensar os modos de entender o papel da crítica e seu modo de articulação. 0 próprio Castro Rocha elaborou uma hipótese para enfrentar o problema, desenvolvida amplamente no livro Por uma esquizofrenia produtiva (2015). A hipótese segue o problema do afastamento da crítica literária em relação à formação de leitores, o que ele já havia demonstrado na obra anterior que se trata de um processo histórico subjacente à institucionalização dos cursos de Letras nas universidades brasileiras, o que levou a crítica cada vez mais dirigir-se basicamente para os pares. A tomada de posição, então, delineada pela noção de esquizofrenia produtiva, como o próprio título já introduz, tem como tese a ideia de que a crítica deve ser uma produção dialógica, atuando em duas perspectivas simultâneas: a produção do conhecimento na universidade, respondendo aos problemas da teoria da literatura, e a que pensa maneiras nas quais a literatura, como conhecimento, possa atuar na formação dos sujeitos.

A esquizofrenia produtiva, por sua vez, pode ser ampliada quando pensamos no sujeito que atua no campo da crítica e da criação ao mesmo tempo. Talvez sejam esses os casos nos quais se possa constatar a noção de esquizofrenia levada ao seu limite. Essa é a tese defendida por Alberto Pucheu: “[...] para o novo pensamento teórico e crítico brasileiro, para que esteja à altura da poesia, da literatura, hoje e sempre praticada neste país, é a necessidade de um pensamento poético-crítico-teórico a partir da literatura não ser nem se querer cinzento, mas tão verdejante e áureo, tão colorido, quanto a obra que ele aborda" 
(PUCHEU, 2014, p. 181). Pelo colorido, além do cinzento, aliás, título de outro livro de Alberto Pucheu, lança luz ao que vem sendo produzido de mais original no campo da crítica literária brasileira nas duas primeiras décadas do Século XXI.

Vimos um acirramento de uma produção anfíbia, para lembrarmos o problema posto por Silviano Santiago, no início dos anos 2000. O que Santiago entende como uma literatura anfíbia pode ser lido, metaforicamente, como o DNA da literatura brasileira considerada marginal, isto é, a forma literária que se deixa contaminar pelo campo crítico, político e social. O ponto de inflexão do fazer da crítica na contemporaneidade está comprometido em desconfiar do olhar cosmopolita que se relaciona com a obra pelo viés da tradição literária ocidental, sobretudo a partir de noções estéticas já bem definidas, o que garantiria, segundo esse pensamento teórico, não só a imparcialidade da crítica como também a forma mais objetiva de alcançar a pureza de uma obra.

Esse é um processo histórico que definiu, e de forma ainda mais intensa, excluiu muitas obras e autores do cânone, sobretudo porque tais perspectivas teóricas rejeitam, como argumenta Silviano Santiago, "a priori as obras que se definem pelo caráter anfíbio" (SANTIAGO, 2008, p. 68). Nesse sentido, o trabalho da crítica literária no Brasil fez o trabalho de limpar do horizonte de leitura - e do que se considera como literatura - autores e obras cujas formas literárias convidam à contaminação de visões.

Mal comparando, o que a crítica-poética tem feito, portanto, é chafurdar a lama e se sujar da produção relega ao lodaçal social e político, no Brasil. A contaminação, então, é a forma literária anfíbia por excelência, pois “[...] requer a lucidez do criador e também do leitor, ambos impregnados pela condição precária de cidadãos numa nação dominada pela injustiça" (SANTIAGO, 2008, p. 69). É a partir desse processo de metamorfose, da lama ao caos, para lembrar da obra de Chico Science (1994), que gostaríamos de ler e produzir criticamente. A língua advinda desse movimento do manguebeat de Science é a dos homens-caranguejos, os quais dividem o mesmo espaço e estão em comunhão, como bem lembrou o sociólogo Josué de Castro: "São seres anfíbios - habitantes da terra e da água, meio homens e meio bichos. Alimentados na infância com caldo de caranguejo - este leite de lama -, se faziam irmãos de leite dos caranguejos." (CASTRO, 1967, p. 18). Da língua dos homens-caranguejos, ocupantes de um espaço dos restos e dos depósitos, podemos tomar a ideia da metamorfose, que de lama se transforma em berçários a muitas espécies. 0 mangue, portanto, pode ser entendido aqui como um espaço anfíbio, híbrido, no qual a disposição dos discursos é marcada por sua condição diversa ${ }^{3}$.

\footnotetext{
${ }^{3}$ Ao tocar nesse assunto, não podemos nos desviar do contexto no qual esse texto foi escrito. No momento em que o Brasil sobre o seu pior ataque a todos os modos de vida no país, um dos biomas sistematicamente atacados foi exatamente o mangue. Em decisão completamente descabida, o Conama (Conselho Nacional do Meio Ambiente), no dia 28/09/2020, revogou as Resoluções 302 e 303/2002, dispõem sobre Áreas de Preservação Permanente (APPs) de reservatórios artificiais e o regime de uso do entorno, e sobre parâmetros, definições e limites de APPs, respectivamente. Essas, que eram as únicas resoluções que asseguravam, legalmente, a proteção dos manguezais e restingas, ao serem desconsideradas, colocam em risco a sobrevivência desse ecossistema.
} 
A crítica suja de lama, nesse sentido, pode ser entendida aqui como um posicionamento político que visa romper com uma certa ideia de literatura e de crítica literária. Mergulhar na lama das obras destinadas à margem é o que estamos entendendo como uma prática situada, pois exige do crítico o movimento de saída de seu espaço habitual e abrir-se para a convivência. Um dos movimentos mais acentuados nesse processo é o da produção da poesia periférica. Para que o trabalho de leitura crítica, reflexão e compreensão das manifestações poéticas da periferia possam ser compreendidas em sua dimensão mais profícuo, o crítico precisa situar-se no espaço em que tais manifestações acontecem, estabelecer um processo de convivência com os artistas e estar aberto a dialogar com a diversidade cosmológica que envolve o processo de criação dos artistas da periferia.

O trabalho da antropóloga brasileira Érica Peçanha do Nascimento com as literaturas de periferia do contexto paulistano é um exemplo dessa prática situada. Esse alargamento teórico e crítico, nas palavras de Érica Nascimento, dentre outras possibilidades, "apresenta instigantes novidades empíricas para o debate acadêmico" (NASCIMENTO, 2019, p. 19). É com essa lente que lemos, por exemplo, a produção poética de Meimei Bastos, uma das organizadoras do Slam Q'brada. A poesia de Meimei Bastos aponta para uma poética da teimosia, como os versos de "Teimosia" revelam:

\author{
quando me perguntaram o que era ser \\ busquei no que hoje não sou \\ pra dizer \\ que \\ fui criança morena \\ sem cor \\ mulher mulata \\ sem raça \\ [...] \\ mesmo que a mim fique imposto \\ o nada \\ que me obriguem a ser \\ um ser sem direito \\ sou calo em mãos e pés \\ resistentes \\ a teimosia nas universidades \\ excludentes \\ o compromisso da continuidade \\ da luta de um povo \\ sou a resistência ao não!
}

(BASTOS, 2019, p. 172-173)

O poema força o leitor a se movimentar historicamente. Tirar o sujeito de um eixo historicamente definido e teoricamente marcado é a tarefa da teimosia. Nesse sentido, o poema enfrenta uma das grandes questões metafísicas da história, a saber, a questão do ser. Todavia, as respostas dadas pela filosofia ocidental ao longo da história ainda não conseguiram abranger a formação das subjetividades de quem pensa fora do paradigma 
hegemônico do campo da subjetividade.

A questão que chama atenção diz respeito diretamente aos sujeitos e aos corpos não visados por essa tradição filosófica, os quais, por meio de uma prática crítico-poética vêm se colocando no debate, como apontam os primeiros versos do poema de Meimei Bastos: a criança morena, a mulher mulata sem raça, são corpos destituídos, a priori, de suas condições ontológicas no pensamento ocidental. Quando o sujeito-mulher mulata se posiciona, não é difícil observar qual foi o espaço a ela destinado: mesmo que a mim fique importo/o nada/que me obriguem a ser/um ser sem direito. Será exatamente pelo segundo movimento fenomenológico que a mulher tomará consciência de si para situar-se física e historicamente no tempo e no espaço, qual seja, o reconhecimento de seu corpo. Sou calo em mãos e pés, diz o verso, que fissura os sentidos históricos do Brasil, uma vez que o calo nas mãos denuncia toda a exploração de corpos e pessoas que, com a força braçal em trabalhos brutalmente exploradores, construíram a força do progresso de um país; mas é também um calo dos pés, no sentido da resistência de corpos e pessoas que passaram a ocupar espaços renegados, como o da universidade (excludente, grita a voz do poema!). Exclusão reforçada pelo conhecimento, restrito à erudição de poucos e com circulação reduzida a grupos privilegiados.

O corpo da mulher mulata sem raça é a fissura no espaço intelectualizado da produção do conhecimento. O reconhecimento de si passa, nesse caso, absolutamente pelo reconhecimento do corpo, inclusive entendendo a corporalidade como uma caixa de ressonância da voz que performatiza o discurso poético para situar-se no mundo. Em outro poema de Meimei Bastos, a centralidade do corpo é ainda mais forte:

Diz do autoamor, ou siririca

quando menina me diziam:

SE TOCA!

se comporta,

senta direito,

fecha essas pernas,

isso não é coisa de menina!

não pode isso,

não pode aquilo.

SE TOCA!

$[\ldots]$

e da infância resistente eu carreguei a

teimosia,

fiz TUDO ao contrário.

SE TOCA!

e, então eu me toquei. toquei meus cabelos, meus lábios, 


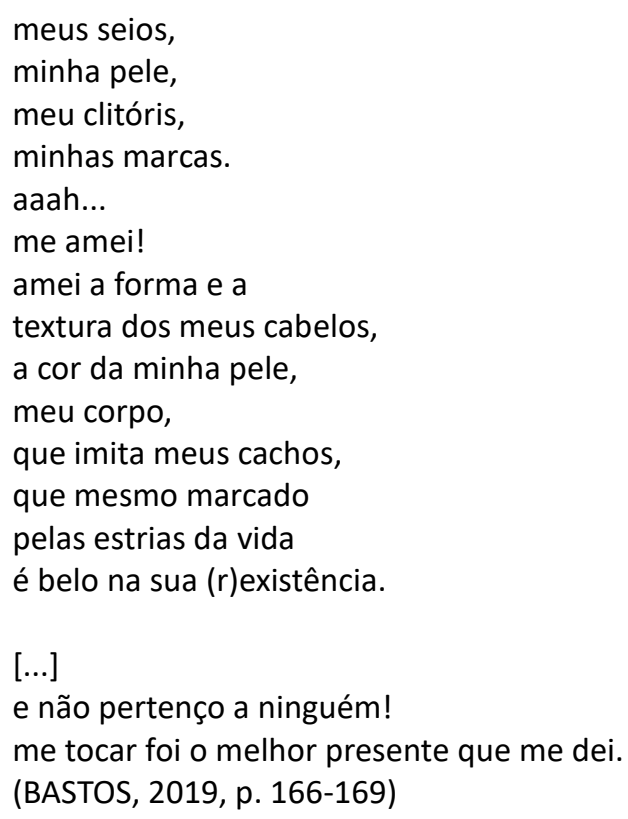

A poeta explora a ambiguidade da interjeição "se toca", que em um sentido violento e excludente, pode significar o cerceamento de espaços e de direitos, como se nota na primeira estrofe do poema, e de outro abre o campo semântico da expressão para o erótico, o corpóreo e a manifestação do desejo. O processo de tomada de consciência do sujeitomulher se dá na autoconsciência de seu corpo como um lugar de passagem, de seus direitos, de suas identidades, de seus desejos eróticos, sexuais, mas também sentimentais e imaginários. Os dois poemas de Meimei Bastos evocados aqui reforçam o caráter de inespecificidade do poético e do político, do ético e do estético, no que concerne, sobretudo, aos diferentes modos com que se apresentam: poema e prosa, teoria e oralidade, processo e performance. Estando entre um e outro e sendo todos ao mesmo tempo, o poético se mantém em uma zona de suspensão, de indefinição, forçando a crítica a se situar no tempo e no espaço mesmo em que o poético se dá.

Nesse sentido, a crítica se lança a um estado de risco ao ser menos um lugar de afirmação de teorias e de juízos e mais um lugar de passagem entre os discursos que atravessam o poético. O pendor crítico demanda, também e a seu modo, uma "situação performancial" ligada à leitura. Paul Zumthor, em sua obra Performance, recepção, leitura (2000), ao apresentar as várias dimensões da voz, considera a leitura como um ato poético performancial:

\footnotetext{
A leitura 'literária' não cessa de trapacear a leitura. Ao ato de ler integra-se um desejo de restabelecer a unidade da performance, essa unidade perdida para nós, de restituir a plenitude - por um exercício pessoal, a postura, o ritmo respiratório pela imaginação. Esse esforço espontâneo, em vista da reconstituição da unidade, é inseparável da procura do prazer. (ZUMTHOR, 2000, p. 67).
}

Abrindo o campo da crítica para um espaço expandido, de copertencimento, a leitura 
não deve se restringir ao arcabouço teórico que sustenta uma tese e comprova uma hipótese, mas sim como uma intervenção criativa. É preciso que a atividade crítica esteja situada ao ponto de perceber que os atores e participantes da poesia periférica expressam as suas experiências, de modo que não é mais possível sentarmos atrás de nossos computadores e fazer uma análise do eu-lírico. A voz performada nos saraus das periferias é um ato poético-político muito além da tradição do eu-lírico e da chamada crise da tradição da poesia moderna. A manifestação poética, como ponderam Magalhães e Pucheu no que tange à discussão da poesia contemporânea, é percebida mais como

\begin{abstract}
gesto do que como "pós-utópica", não atestando sua diferença em uma marcação temporal naquilo que ela se vincula ou deixa de ser vincular em relação à vanguarda, mas naquilo que atesta sua contemporaneidade: colocando-se na obscuridade do tempo não de forma elucidativa, comunicativa, clara, mas de maneira também obscura, cifrada, enigmática, informe, respondendo a uma exigência à qual ela não pode responder senão se pondo em risco, em ilegibilidade, em um limite tal que em sua abertura também cabe a ideia, a potência de voz. (MAGALHÃES; PUCHEU; 2017, p. 22 grifo no original).
\end{abstract}

Outras poetas que insurgem da cena periférica são Luz Ribeiro e KIMANI. Ambas, assim com Meimei Bastos, evidenciam o eu poético periférico. Uma forma de dialogar teoricamente com os poemas produzidos nesses contextos socioculturais é mobilizar as teorias advindas do campo literário produzidas por elas próprias. No ensaio "Erguer a voz: pensar como feministas, pensar como negra", de bell hooks ${ }^{4}$ (2019), encontramos o modo como a mulher se situa no campo de disputa poético e político em que expressa suas manifestações estéticas:

para construir a minha voz, eu tinha que falar, me ouvir falar - e falar foi o que fiz -, lançando-me pra dentro e pra fora de conversas e diálogos de gente grande, respondendo a perguntas que não eram dirigidas a mim, fazendo perguntas semfim, discursando. (hooks, 2019, p. 32).

No poema "mulher de palavra", de Luz Ribeiro, a voz que se apresenta ao leitor desvela quem é essa mulher de palavra, como é delineada, composta, inscrita, circunscrita por meio do papel-corpo que a compõe, espaço no qual a celulite do corpo possui a mesma densidade da celulose. Corpo e papel ao mesmo tempo.

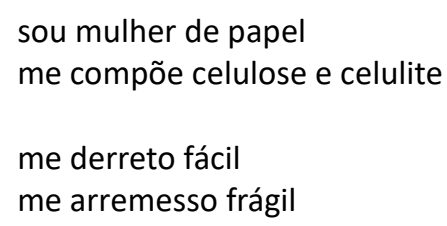

\footnotetext{
${ }^{4}$ Grafamos o nome de bell hooks sem as maiúsculas iniciais em respeito à própria autora que assina seu nome dessa forma.
} 
me quiseram ágil

eu leito, tento

(RIBEIRO, 2017, p. 18)

Na segunda estrofe do poema, o pronome pessoal oblíquo "me" refere-se à primeira pessoa do singular, o eu, que assim como o papel, resiste à ação do tempo e dos fenômenos. Em outro trecho do poema, a voz do eu-mulher conduzirá o leitor a um lugar de silenciamento, de solidão, espaço forçadamente de acomodação atribuído à mulher. A força, que transcende através do cabelo em riste amolece quando se entende o ser/estar no mundo. O jogo de palavras, o paradoxo entre o estável e o instável, é a mulher de palavra circunscrita entre os processos de escolha, o que esperam desse eu e o que esse eu realmente é ou não é. O poema se constrói nesse jogo da indiscernibilidade do eu:

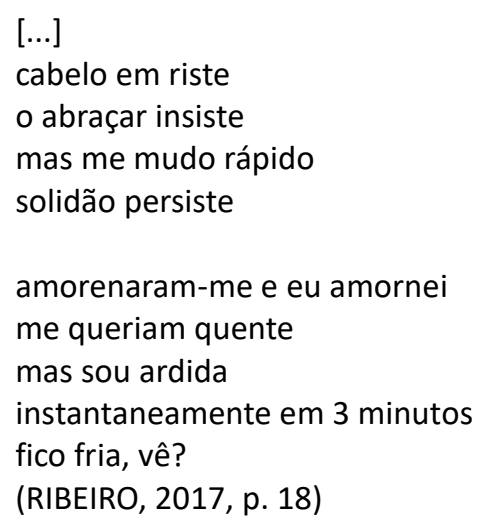

Para Audre Lorde, "na transformação do silêncio em linguagem e em ação, é essencial que cada uma de nós estabeleça ou analise seu papel nessa transformação e reconheça que seu papel é vital nesse processo". (LORDE, 2019, p. 54). A palavra poética, portanto, como verbo conjugado, provoca o leitor a analisar as condicionantes do existir e ser mulher. $\mathrm{Na}$ extensão do poema notamos o caráter transformador por meio da manifestação poética:

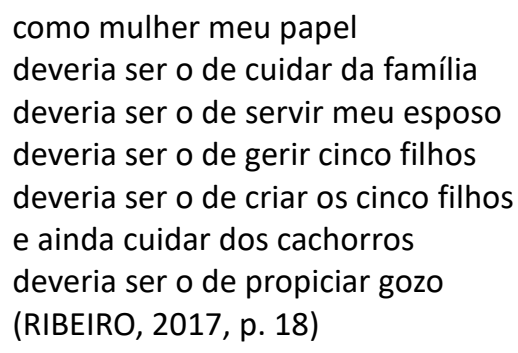

A palavra deveria, forma conjugada do verbo dever, no futuro do pretérito simples, indica uma ação que poderia ter ocorrido após determinada situação. No entanto, a potência da palavra poética leva os sentidos do verbo para o campo da probabilidade, da incerteza e da dúvida, promovendo um descolamento do eu em relação a um estado fixo de suas ações. 
O poema, nesse sentido, acaba afirmando o que a mulher não precisa ser, ou melhor, nas afirmações condicionadas dos versos, o poema se refere a fatos que não se realizaram e que, provavelmente, não se realizarão, a não ser no campo do prazer, e se assim for, que seja pelo próprio prazer de ser. Ao se colocar no campo do possível, a mulher encontra-se, portanto, na ambiguidade entre exercer um papel e ser o próprio papel:

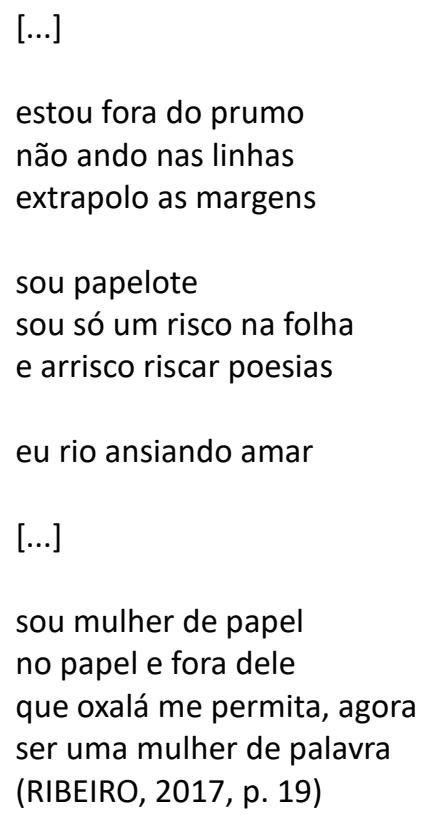

Ao final, o poema se apresenta como um longo pensamento sobre a própria poesia, e sobre como o endereçamento ao outro, no qual o sujeito sempre está em risco, em deslocamento tensivo e intensivo, é parte constitutiva da escrita. Nesse sentido, na aliteração "arrisco riscar", tem-se o movimento de erguer a voz na palavra, para além das beiradas, fora delas e dentro delas, sob as bênçãos de Oxalá que abrem os caminhos para ser uma mulher de palavra. A resistência se dá desde a escrita, que resiste a si mesma e transborda as margens, em um movimento hesitante que rompe com o paradigma da linha reta e dos sentidos lineares, de modo que a palavra ganha força no ato performático, conjugada pelos cortes e repetições.

O verso "eu rio ansiando amar" aponta para a potência de enunciação do poético expandindo a possibilidade de deslocamento de sentidos, que podem figurar desde o "rio" para o "mar", mas também do "sorriso" ao "ato de amar". O verbo "ansiar", entre o "rio" e o "mar" aponta para o esgarçamento dos horizontes de sentidos, é um anseio desde a escrita que deseja a expansão dos espaços, corroborando a ampliação dos sentidos do poema em sua expressão poética. O poema como lugar de enunciação mostra-se, então, como ferramenta ativa no processo não de romper o silêncio de uma voz calada, mas antes, de alterar a força, a potência e os sentidos do poético. Essa leitura pode ser corroborada com a afirmação de bell hooks, para quem "[...] nossa luta (das mulheres negas) não tem sido para emergir do silêncio para a fala, mas para mudar a natureza e a direção da nossa fala, para 
fazer uma fala que atraia ouvintes, que seja ouvida". (hooks, 2019, p. 32-33).

Já o poema de Kimani, intitulado pelo verso que se repete ao longo do poema "TÔ PELA LUANA, PELAS MANAS, PELAS XANAS, XOTAS", entendido aqui como um refrão, uma entoação que se apresenta quatro vezes ao longo de todo o poema, sempre antes de iniciar cada estrofe, o que nos remete ao um abrir e fechar de ciclos. Consideremos as duas últimas estrofes do poema que seguem a partir do refrão. O poema é todo construído na linguagem coloquial, linguagem do dia a dia, da "gramática do cotidiano", para utilizarmos a expressão de Conceição Evaristo (2019, p. 14), ou do "pretuguês", de Lélia Gonzalez (2019, p. 345).

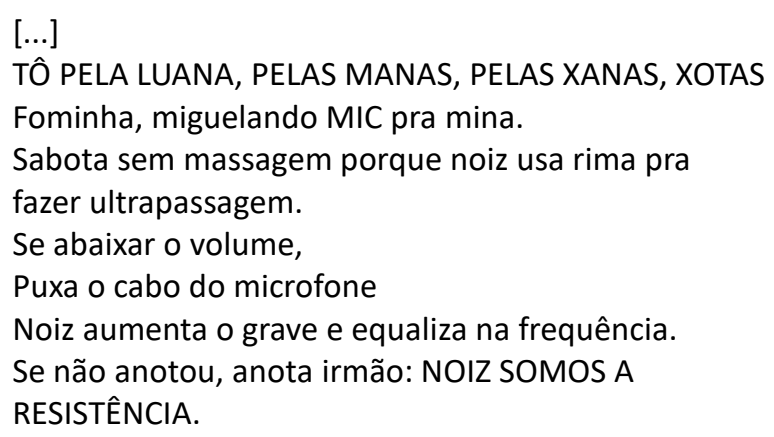

O poema é uma autorreferência à performance poética do Slam. O substantivo "fominha", jargão já bastante utilizado no contexto do futebol, se refere ao jogador que não passa a bola para o companheiro, como um ato de heroísmo barato. Assim como no futebol, o Slam é um jogo (poético) em que o sentimento de comunidade prevalece em detrimento ao de individualismo. Nesse ponto, temos uma implicação ética e política no modo de entender o ser periférico, de modo que o senso coletivo é imprescindível para se pensar a poesia das periferias. A luta e a resistência são um processo que diz respeito à sobrevivência da comunidade, e, portanto, deve ser um ato compartilhado, e não uma ação heroica de um indivíduo que busca para si a glória. No mesmo sentido, o termo "Miguelando" significa não dividir algo, palavra que repete e amplia o sentido de individualidade de "fominha".

Por fim, MIC é a abreviação de microfone, grafado em maiúsculo devido sua essencialidade nas competições de Slam. MIC também convoca a presença e a materialidade da voz, a qual, se vale de "rimas" para fazer a ultrapassagem. As rimas, nesse contexto, não significam apenas o jogo sonoro das terminações em ABBA, além, são o ritmo e a sonoridade própria que denunciam o pertencimento. Sobre esse aspecto da singularidade da autoria, a crítica Lucia Tennina argumenta:

As formas de falar e de rimar, de aproximar-se do microfone, de ficar em pé, os movimentos das mãos e dos próprios corpos - que, muitas vezes, evidenciam cicatrizes, doenças e cansaço, ou músculos -, a presença e o caráter são afirmações do "ser periférico" que, por meio da repetição, instala esquemas motrizes que naquele ambiente tornam-se reconhecíveis e valorizáveis. (TENNINA, 2013, p. 18). 
Nesse sentido, o poema coloca como questão a posição que o sujeito ocupa. No caso específico do poema de Kimani, o espaço ocupado pelas mulheres, pelas manas, xanas e xotas, e o espaço cantado pela voz da mulher. Trata-se de uma formalização estética que retrata o que é peculiar do contexto da periferia. Concordando com Lorde, falamos aqui "da poesia como destilação reveladora da experiência, não do estéril jogo de palavras (LORDE, 2019, p. 46).

$\mathrm{Na}$ última estrofe do poema notamos o ato de reivindicação, dirigido abertamente ao leitor - e por extensão ao crítico -, de respeito às minas.

\author{
TÔ PELA LUANA, PELAS MANAS, PELAS XANAS, XOTAS \\ Kimani vai desenhar, \\ Noiz equilibra com dedo a torre de pisa e faz \\ Babilônia cair no sussurro e já disse Casmurro: \\ "Cigana oblíqua e dissimulada" \\ As minas são sinônimo, heterônimo, pretérito mais que perfeito, conceito, feito, \\ mais respeito \\ RESPEITO É PRA QUEM TEM - Respeita as mina, vacilão, ou então fica aí se \\ contorcendo de machismo e arrogância no chão.
}

(KIMANI, p. 20, 2018).

Uma vez mais o processo de reivindicação da palavra poética irrompe pela tomada de consciência do corpo, ainda que na sua precariedade. O "dedo na torre de pisa" funciona como metáfora do desejo que perpassa todo o corpo. A imagem da Torre de Pisa inclinada, assim como o próprio dedo que se inclina ao desejo em direção ao gozo, são indicativos dos sentidos do poema que se inclinam ao mesmo tempo para o espaço da insurgência. Adiante, a intertextualidade recuperada do famoso enigma de Dom Casmurro, de Machado de Assis, apresenta o eu-devasso, que reivindica para além do respeito, espaço, abertura, lugar de fala e de escuta. A obliquidade se expande dos olhos de Capitu para os dedos e desejos das manas. Jade Quebra, em participação na música "Trincheira", do Slam das Minas SP, resume bem na linguagem da quebrada a última estrofe: "na contra mão das linguagem/ Eu to lixando se os boy num entendeu/ "Criptogragiria"/ Num codifico/ Esse é o mistério da quebra/ Mosco o cabelo avuô".

Diante da "criptogragiria", diante da realidade extenuante e oblíqua exposta pela palavra, diante do sujeito poético que se posiciona corporal e politicamente no ato performático da palavra, o posicionamento da crítica de poesia e sua leitura se vê implicada em uma dimensão de alteridade. Em lugar de se posicionar no espaço que lhe seria próprio, ou de falar do que seria o próprio, o papel da crítica de poesia demanda uma inadmissibilidade de qualquer negação do outro. No caso da literatura marginal feminina, ocorre uma preocupação ainda maior, uma vez que o poético é a via pela qual se afirma um posicionamento, não só pela diferenciação em relação aos grupos hegemônicos, mas sobretudo em relação ao domínio masculino nas periferias, o que abre uma fissura no modo como percebemos a complexidade desse posicionamento.

Essa tomada de posição da crítica, quando situada, não se desvencilha de uma 
intervenção política e ética. Participar do momento em que certa poesia atual se faz, sobretudo a poesia feita por mulheres, que conjuga discursos atravessados pelo testemunho, pelo autobiográfico, pelo (in)familiar, e que muitas vezes assume um tom militante e panfletário, é coparticipar da construção de um pensamento que possa partilhar as experiências, próprias e alheias, e fazer do vivido o escopo poético, teórico e político da poesia.

\section{Considerações Finais}

Em suma, a poética da quebrada de mulheres alinhadas a teorias de mulheres evidencia outras análises antes não abarcadas pela hegemonia literária. A poesia feita por mulheres transcende o jogo de palavras, é parte da vivência, das reminiscências, do traquejo do universo mulherio. No contexto periférico, as poetas ainda têm que lidar com um lugar relegado à subalternidade literária, vivenciando uma dupla exclusão, colocadas com as outras dos outros. "É a partir dessa dupla exclusão que as escritoras articulam seus discursos a fim de superar a condição de estar "sujeitas a uma posição" para virem a ocupar também elas uma "posição de sujeito". (TENNINA, 2017, p. 175).

Nessa posição de sujeitos das suas próprias poéticas, narrativas, escrevivências, entendemos que a poesia cria um espaço por meio da linguagem para expressar e registrar esse levante revolucionário, sobretudo um discurso poético-político que busca a afirmação e a implementação da liberdade.

É dessa relação do entrelaçamento poético das margens, de mulheres das margens, de mulheres negras das margens, dessa coletividade, dessa umbigada poética, dessa punga, desse espiral poético que vem agregando mulheres que escrevem de um outro lugar, sobre um outro lugar, a partir de uma outra experiência, que observamos o encontro de um corpo de mulher negra com outro corpo, o da crítica, de forma a compor um todo mais potente que, ao mesmo tempo que marca a presença de uma voz heterogênea, também expõe o horror, a violência e o próprio violador em seu limite, desde dentro, expondo-o, expondo a poesia no limite do outro.

\section{Referências}

ADORNO, Theodor W. Educação - para quê? In: . Educação e emancipação. Trad.

Wolgang Leo Maar. 4. ed. Rio de Janeiro: Paz e Terra, 2006. p. 139-168.

ANDRADE, Mário. O empalhador de passarinho. São Paulo: Livraria Martins Editora, 1972. BASTOS, Meimei. Diz do autoamor, ou siririca. In: DUARTE, Mel. Querem nos calar: poemas para serem lidos em voz alta. DUARTE, Mel (org.). São Paulo: Planeta do Brasil, 2019, pp. 166-169.

BASTOS, Meimei. Teimosia. In: DUARTE, Mel. Querem nos calar: poemas para serem lidos em voz alta. DUARTE, Mel (org.). São Paulo: Planeta do Brasil, 2019, pp. 172-173. 
BENJAMIN, Walter. Experiência e Pobreza. In: . O anjo da história. Tradução de João Barrento. Belo Horizonte: Autêntica, 2018, p. 83-90.

CASTRO, Josué de. Homens e Caranguejos. São Paulo: Editora Brasiliense, 1967. DOMENECK, Ricardo. Ideologia da percepção ou algumas considerações sobre a poesia contemporânea no Brasil. Revista Inimigo Rumor, Rio de Janeiro, n. 18. 2o semestre 2005/1ㅇosemestre 2006, p. 175-216, 2006.

EVARISTO, Conceição. Prefácio. In: Querem nos calar: poemas para serem lidos em voz alta. DUARTE, Mel (org.). São Paulo: Planeta do Brasil, 2019, pp. 13-15.

FRANCHETTI, Paulo. Crítica literária: algumas reflexões intempestivas. Revista terra roxa e outras terras, Londrina, v. 32, p. 115-123, 2016. Disponível em:

http://www.uel.br/revistas/uel/index.php/terraroxa/article/view/30197/21424. Acesso em: 15 de abril de 2019.

GARRAMUÑO, Florencia. O império dos sentidos: poesia, cultura e heteronomia. In: PEDROSA, Célia (org.); ALVES, Ida (org.). Subjetividades em devir. Rio de Janeiro: 7 Letras, 2008, pp. 82-91.

GINZBURG, Jaime. Periódicos acadêmicos: Antagonismo entre produção e leitura (notas sobre revistas da área de Letras publicadas em 2013). Revista Expedições: Teoria da História \& Historiografia, vol. 5, n. 1, jan.-jul. 2014. Disponível em:

https://www.revista.ueg.br/index.php/revista geth/article/view/3059. Acesso em: janeiro de 2015.

GONZALES, Lélia. A categoria político-cultural da Amefricanidade. In: HOLLANDA, Heloisa Buarque (org). Pensamento feminista - conceitos fundamentais. Rio de Janeiro: Bazar do tempo, 2019, p. 341-356.

hooks, bell. Erguer a voz: pensar como feminista, pensar como negra. Tradução de Cátia Bocaiuva Maringolo. São Paulo: Elefante, 2019.

KIMANI. TÔ PELA LUANA, PELAS MANAS, PELAS XANAS, XOTAS. In: SLAM DAS MINAS SP (org.). Mudas: falas são sementes em germinação. São Paulo: Conecta Brasil, 2018, p. 20. LORDE, Audre. Irmã outsider. Tradução Stephanie Borges. Belo Horizonte: Autêntica Editora, 2019.

MAGALHÃES, Danielle; PUCHEU, Alberto. A poesia como um gesto em “Rebotalho", de Masé Lemos, e em "Um teste de resistores", de Marília Garcia. SEDA -Revista de Letras da Rural/RJ. Seropédica/RJ, v.2, n.4, jan./abri., 2017, p.8-24. Disponível em:

https://www.revistaseda.org/index.php/seda/article/view/47/35. Acesso em: 09 de outubro de 2020.

MORRISON, Toni. A origem dos outros: seis ensaios sobre racismo e literatura. Tradução Fernanda Abreu. São Paulo: Companhia das Letras, 2019.

NASCIMENTO, Érica Peçanha. Literatura e Periferia: considerações a partir do contexto paulistano. In: DALCASTAGNÈ, Regina (org.); TENNINA, Lucia (org.). Literatura e Periferias. Porto Alegre: Zouk, 2019, p. 15-38.

PUCHEU, Alberto. Apoesia contemporânea. Rio de Janeiro: azougue, 2014.

SANTIAGO, Silviano. Uma literatura nos trópicos. Rio de Janeiro: Rocco, 2000. 
SANTIAGO, Silviano. Uma literatura anfíbia. In: O cosmopolitismo do pobre: crítica literária e crítica cultural. Belo Horizonte: Editora UFMG, 2008, p. 64-73.

SCHEEL, Marcio. O primado do pensamento em série - De como produzir ciência faz divisa com fabricar chuveiros. Revista Insight Inteligência. São Paulo, ano XX, № 78 jul/ago/set., 2017, p. 104-119. Disponível em: https://www.insightinteligencia.com.br/pdfs/78.pdf. Acesso em: 20 de setembro de 2020.

SCIENCE, Chico; NAÇÃO ZUMBI. Da lama ao caos. Rio de Janeiro: Chaos, 1994 RIBEIRO, Luz. Estanca. São Paulo: Quirino Edições, 2017.

ROCHA, João Cezar Castro. Crítica literária: em busca do tempo perdido? Chapecó: Argos, 2011.

ROCHA, João Cezar Castro (org.); PRIGOL, Valdir (org.). Por uma esquizofrenia produtiva: (Da prática à teoria). Chapecó: Argos, 2015.

ROMÃO, Luiza. FADIGA. In: DUARTE, Mel. Querem nos calar: poemas para serem lidos em voz alta. São Paulo: Planeta do Brasil, 2019. p. 117.

TENNINA, Lucia. Saraus das periferias de São Paulo: poesia entre tragos, silêncios e aplausos. Estud. Lit. Bras. Contemp. [online]. 2013, n.42, pp.11-28. Disponível em:

https://www.scielo.br/scielo.php?pid=S231640182013000200001\&script=sci abstract\&tlng=es. Acesso em: janeiro de 2020.

TENNINA, Lucia. Cuidado com os poetas! Literatura e periferia na cidade de São Paulo. Tradução Ary Pimentel. Porto Alegre: Zouk, 2017.

ZUMTHOR, Paul. Performance, recepção, leitura. São Paulo: Educ, 2000

Recebido em: $12 / 10 / 2020$

Aceito em: $17 / 11 / 2020$ 